\title{
Updated diagnostic \& prognostic paradigm for CAD: a narrative review
}

\author{
Patrizia Toia $^{1}$, Ludovico La Grutta ${ }^{2}$, Tommaso Smeraldi ${ }^{1}$, Francesco Agnello ${ }^{1}$, Emanuele Grassedonio ${ }^{1}$, \\ Erica Maffei ${ }^{3}$, Massimo Midiri ${ }^{1}$, Filippo Cademartiri ${ }^{4}$
}

${ }^{1}$ Department of Biomedicine, Neurosciences and Advanced Diagnostic (BiND), University of Palermo, Italy; ${ }^{2}$ Department of Health Promotion Sciences Maternal and Infantile Care, Internal Medicine and Medical Specialities (ProMISE), University of Palermo, Italy; ${ }^{3}$ Department of Radiology, Area Vasta 1, ASUR Marche, Urbino (PU), Italy; ${ }^{4}$ Department of Radiology, SDN IRCCS, Naples, Italy

Contributions: (I) Conception and design: All authors; (II) Administrative support: None; (III) Provision of study materials or patients: None; (IV) Collection and assembly of data: All authors; (V) Data analysis and interpretation: All authors; (VI) Manuscript writing: All authors; (VII) Final approval of manuscript: All authors.

Correspondence to: Filippo Cademartiri. Department of Radiology, Area Vasta 1, ASUR Marche, Urbino (PU), Italy; Department of Radiology, SDN IRCCS, Naples, Italy. Email: filippocademartiri@gmail.com.

\begin{abstract}
Cardiovascular diseases are the first cause of death globally; early detection of coronary artery disease $(\mathrm{CAD})$ is a challenge for clinicians and radiologists. Over the past 2 decades there have been several improvements in the methods for the assessment of diagnosis and prognosis in patients with suspected CAD; most of these methods are imaging methods and they operate with high-end technologies. Cardiac computed tomography (CCT) as we know it today was introduced in 1998 and has ever progressed with constant pace. The first decade was the technical validation phase of the method while the second decade was the clinical validation phase. CCT has developed an excellent diagnostic and prognostic value; technological development together with radiation dose reduction, contributed to the widening of its clinical indications. The diagnostic value of CCT is particularly important as a first line in symptomatic patients with suspected obstructive CAD and low-to-intermediate cardiovascular risk. It is a test that should come, whenever possible, in front of functional evaluation because of its very high sensitivity and negative predictive value. The prognostic value of CCt is still investigational, even though it is becoming quite evident that the atherosclerotic phenotype plays a major role in the determination of prognosis, and as consequence, in the individualization of optimal pharmacological therapy, especially in the cohort without significant obstructive CAD. Recently, scientific and practical guidelines have been updated taking into account the role of CCT, which is able to provide a reliable and fast diagnosis with an additional resources optimization. Multiple registries and trials have been developed and will be summarized in this review. Recent guidelines highlighted the role of CCT in diagnosing suspected CAD.
\end{abstract}

Keywords: Coronary artery disease (CAD); cardiac computed tomography (CCT); atherosclerosis; diagnosis; prognosis; therapy; optimal medical therapy (OMT)

Submitted May 22, 2020. Accepted for publication Sep 23, 2020.

doi: $10.21037 / \mathrm{cdt}-20-526$

View this article at: http://dx.doi.org/10.21037/cdt-20-526

\section{Introduction}

According to World Health Organization, cardiovascular diseases are the first cause of death globally; thus, people at high cardiovascular risk need early detection of coronary artery disease (CAD) to reduce related mortality and morbidity (1). Since CAD represents an important cost for health services, guidelines and diagnostic workup have been modified and updated in the last decades in order to achieve 
Table 1 Diagnostic performance of CCT

\begin{tabular}{|c|c|c|c|c|c|c|c|}
\hline Authors & CT-Slices & $\begin{array}{l}\text { Population } \\
\text { (n) }\end{array}$ & Stenosis (\%) & $\begin{array}{c}\text { Sensitivity } \\
(\%)\end{array}$ & $\begin{array}{c}\text { Specificity } \\
(\%)\end{array}$ & PPV (\%) & NPV (\%) \\
\hline Nikolaou et al. (2) & 64 & 72 & 50 & 97 & 79 & 86 & 96 \\
\hline Ehara et al. (3) & 64 & 69 & 50 & 98 & 86 & 98 & 86 \\
\hline Weustink et al. (4) & Dual source & 100 & 50 & 99 & 87 & 96 & 95 \\
\hline Meijboom et al. (6) & 64 & 360 & 50 & 99 & 64 & 86 & 97 \\
\hline Cademartiri et al. (7) & 64 & 279 & 50 & 100 & 95 & 76 & 100 \\
\hline Opolski et al. (8) & Dual source & 475 & 50 & 98 & 37 & 67 & 94 \\
\hline Lee et al. (9) & 64 & 61 & 50 & 100 & 83.3 & 93.5 & 100 \\
\hline
\end{tabular}

$\mathrm{CCT}$, cardiac computed tomography.

a better and faster diagnosis, in the easier way, reducing public costs. The best technique should be the one with the highest sensitivity and negative predictive value, with the lowest biological and economic costs. Technological development achieved by cardiac computed tomography (CCT) in the last decades, together with radiation dose reduction strategies, contributed to the expansion of clinical indications for CCT. Diagnostic accuracy of CCT, in the identification of coronary stenosis strictly depends on hardware requirements that have improved in recent years. The high spatial and temporal resolution, together with high scanning velocity and high contrast resolution, are crucial for a good cardiac CT scanning. CCT has an excellent prognostic value with an excellent sensitivity and negative predictive value, close to $100 \%$ in more studies (Table 1). Several registries and trials have been developed in the last decade; they changed, step by step, the prognostic paradigm for CAD diagnosis. The purpose of this article is to review the diagnostic and prognostic paradigm for $\mathrm{CAD}$ detection, discussing the results of the principal clinical trials over CCT (Table 2).

We present the following article/case in accordance with the Narrative Review reporting checklist (available at http:// dx.doi.org/10.21037/cdt-20-526).

\section{Methods}

Information sources used to write this article are: World Health Organization's data, the site clinicaltrials.gov, Medline search, web search discussions with experts in the field; hand searches of the references of recovered literature.

\section{Discussion}

\section{Prognostic insights of the CONFIRM registry}

The CONFIRM (COronary CT Angiography EvaluatioN For Clinical Outcomes: An InteRnational Multicenter) registry is a large, prospective, observational study of patients undergoing CCT. CONFIRM study represents a milestone in the diagnosis of coronary heart disease.

The primary purpose of CONFIRM was to assess the prognostic value of CCT findings for the prediction of future adverse cardiac events. In particular, the CONFIRM aimed to study coronary and non-coronary cardiac findings at CCT and integrate them with demographic and clinical data in order to refine the risk stratification in case of suspected or known CAD. The initial registry cohort included patients with suspected CAD who underwent $\geq 64$-detector row CCT at 12 centres in 6 countries (United States, Canada, Germany, Switzerland, Italy, South Korea) between 2005 and 2009. The CONFIRM study included two phases: a first phase included 27,125 patients $(\geq 18$ years of age) with a mean follow-up of $2.3 \pm 1.1$ years for a primary endpoint of all-cause death; a second phase included 4,682 patients in a distinct validation cohort with identical elements to phase I and with event follow-up. Furthermore, several studies on defined subgroups and topics followed the main study (17).

Patients were followed up after CCT in order to 
Table 2 Design of large clinical trials over CCT

\begin{tabular}{|c|c|c|c|c|}
\hline Trial & Acronym & Type of study & Design & Enrolled patients \\
\hline PROMISE (11) & $\begin{array}{l}\text { PROspective Multicenter } \\
\text { Imaging Study for } \\
\text { Evaluation of Chest Pain }\end{array}$ & $\begin{array}{l}\text { Interventional (Clinical } \\
\text { Trial), Randomized, } \\
\text { Parallel Assignment, } \\
\text { Open Label }\end{array}$ & $\begin{array}{l}\text { Anatomical testing with } \\
\text { the use of CCT versus } \\
\text { functional testing }\end{array}$ & $\begin{array}{l}\text { Previously unassessed } \\
\text { patients with worsening or new } \\
\text { suspicious symptoms for CAD } \\
\text { requiring diagnostic tests }\end{array}$ \\
\hline CONFIRM (12) & $\begin{array}{l}\text { COroNary CT Angiography } \\
\text { Evaluation For Clinical } \\
\text { Outcomes: An InteRnational } \\
\text { Multicenter Registry }\end{array}$ & $\begin{array}{l}\text { Observational, } \\
\text { Prospective }\end{array}$ & СCT & $\begin{array}{l}\text { Patients with suspected CAD } \\
\text { undergoing CCT for CAD } \\
\text { assessment as part of the } \\
\text { standard of care }\end{array}$ \\
\hline $\begin{array}{l}\text { PARADIGM } \\
\text { (14) }\end{array}$ & $\begin{array}{l}\text { Progression of } \\
\text { AtheRosclerotic PIAque } \\
\text { DetermIned by Computed } \\
\text { TomoGraphic Angiography } \\
\text { Imaging }\end{array}$ & $\begin{array}{l}\text { Observational [Patient } \\
\text { Registry], Cohort, } \\
\text { Prospective }\end{array}$ & Serial CCT & $\begin{array}{l}\text { Patients with known or } \\
\text { suspected CAD who have } \\
\text { undergone serial CCT } 2 \text { years } \\
\text { after baseline }\end{array}$ \\
\hline $\begin{array}{l}\text { PLATFORM } \\
\text { (15) }\end{array}$ & $\begin{array}{l}\text { Prospective LongitudinAI } \\
\text { Trial of FFRct: Outcome } \\
\text { and Resource IMpacts) }\end{array}$ & $\begin{array}{l}\text { Observational, } \\
\text { prospective }\end{array}$ & $\begin{array}{l}\text { Standard practice } \\
\text { evaluation and treatment } \\
\text { vs. FFRCT }\end{array}$ & Patients with suspected CAD \\
\hline
\end{tabular}

CCT, cardiac computed tomography; ACS, acute coronary syndrome; CAD, coronary artery disease; SIHD, stable ischemic heart disease; FFRCT, fractional flow reserve derived from CT.

identify major adverse cardiac events (MACE) and CADrelated hospitalizations. The presence of CAD diagnosed at CCT conferred an increased risk of mortality, compared to those with normal coronary arteries. One of the main contributions of CONFIRM was the identification of an increased risk of death with the severity of CAD identified in CCT image datasets. The study distinguished the risk according to the age and gender of patients. Patients $\geq 65$ years showed an increased risk of all-cause death for increase of the extent and severity of CAD. On the other side, patients $<65$ years of age had an increased death risk with 2 - and 3 -vessel or left main disease compared to patients $\geq 65$ years; non-obstructive or 1 -vessel CAD mortality had similar rates (18). The women with 3 -vessel or left main disease presented surprisingly a higher probability of death than men; mortality rates did not show significant gender differences for the other categories of CAD in relation to the extension (18). It is also of great interest to observe that patients with normal coronary arteries at CCT showed an excellent prognosis, highlighting the importance of risk stratification on the basis of CAD assessed with CCT (Figure 1) (18).

Villines et al. (19) analysed a population of 10,037 symptomatic patients without known CAD from the CONFIRM registry, who underwent both coronary calcium score (CCS) and CCT. They demonstrated that 

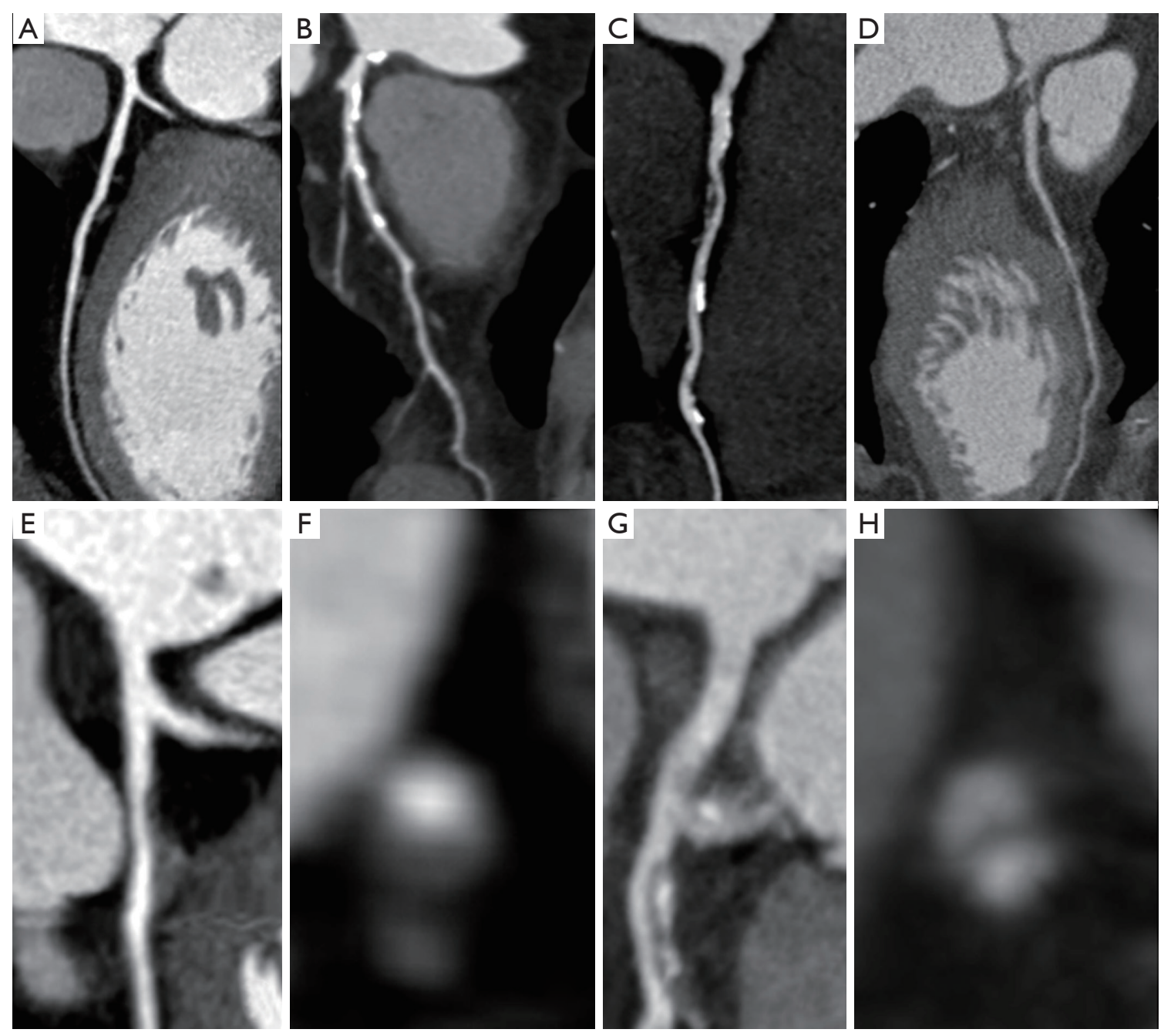

Figure 1 Association of coronary findings at CCT with different outcome: normal coronary artery (A); calcified non-obstructive plaques (B); mixed plaques with moderate stenosis (C); obstructive non-calcified plaque (D); positive remodelling (E,F); unstable plaque with intraplaque dye penetration $(\mathrm{G}, \mathrm{H})$.

5,128 subjects had a CCS of 0 and among them $84 \%$ had no CAD, $13 \%$ had non-obstructive CAD, and $3.5 \%$ had $\geq 50 \%$ stenosis ( $1.4 \%$ had $\geq 70 \%$ stenosis) at CCT. Any obstructive CAD detected by CCT was associated with a significantly increased rate of all-cause mortality. A CCS $>0$ had an excellent negative predictive value (96\%) for stenosis identification $\geq 50 \%$, with a good sensitivity $(89 \%)$; however, specificity (59\%) and positive predictive value (29\%) were lower. Authors demonstrated that among symptomatic patients with a 0 CCS, obstructive CAD may be associated with increased cardiovascular events. The authors concluded that CCS didn't add incremental prognostic information to
CCT image datasets in symptomatic patients (19).

Moreover, 1,226 asymptomatic subjects from the CONFIRM registry, undergoing both CCS and CCT, were evaluated with a 6 years follow-up. Authors demonstrated that CCT findings, in asymptomatic patients, including coronary stenosis severity, plaque composition, and coronary segment location provided incremental prognostic utility, beyond traditional risk factors alone. Furthermore, authors showed that CCT findings did not add any diagnostic benefit if added to a model consisting of both CCS and conventional risk factors; in daily clinical practice of asymptomatic subjects, it could be enough to 
perform a CS together with the assessment of traditional cardiovascular risk factors (20).

A further sub-analysis of the CONFIRM registry evaluated the ability of CCT to predict 5 -year mortality at different ages. Authors analysed CCT results according to age and divided the population into two groups: $<70$ years $(n=7,198)$ and $\geq 70$ years $(n=1,786)$; they found that the segment involvement score (SIS) was predictive of mortality in both groups. The same study showed that CCT findings predicted long-term MACE in both groups (21).

Focusing on the prognosis of chronic total occlusions (CTOs), Opolski et al. (22) analysed a population of 22,828 patients without known prior CAD. Authors showed that the CCT identification of CTOs is associated with an increase of late myocardial revascularizations; however, two-years mortality was comparable to that of patients with moderate/severe CAD (22).

Another sub-analysis evaluated the usefulness of baseline statin therapy in non-obstructive CAD detected by CCT. A gradual increase of risk for all causes mortality was found in the general population by stratification of CCS after adjustment for covariates. Specifically, the gradual relationship between increasing CCS and increased mortality was preserved in patients not receiving statins at baseline. Patients not assuming statins showed higher risks of all-cause mortality according to CCS stratification; however, the higher risk was not found in patients with $\mathrm{CCS}=300$. Another relevant finding was that the risk of MACE was lower in patients already on statin therapy compared to the general population. Focusing on CAD, a gradual rise of all-cause mortality was observed in the general population with increasing stratification of SIS after adjustment of covariates. The risk was attenuated by statin use at baseline. Furthermore, a stepwise increase of the risk of MACE was reported in the overall population by increasing stratification of SIS. The results of this study were of great clinical relevance because the risk of allcause mortality in patients with increasing atherosclerotic burden at CCT even in the absence of obstructive CAD was modified by the presence or absence of baseline statin therapy (23).

Starting from the CONFIRM insights, a clinical risk assessment score was also created, the so-called CONFIRM score; the CONFIRM score combines clinical risk parameters together with the most predictive CCT parameters (composition, location and luminal narrowing). Hadamitzky et al. (24) demonstrated that the best CCT mortality predictors were the number of proximal coronary artery segments with mixed or calcified plaques, and the number of proximal segments with stenosis $>50 \%$. Importantly, some plaque features, studied by CCT, were among the largest incremental predictors of coronary risk (24). During a 5-year follow-up, Deseive et al. (25) demonstrated that CONFIRM score allows a better prediction of mortality compared to traditional clinical risk scores (25).

In the setting of patients with diabetes, Rana et al. (26) showed a higher frequency of obstructive CAD (37\% vs. $27 \%, \mathrm{P}<0.0001)$ and a lower probability to have normal coronary arteries compared to patients without diabetes mellitus ( $28 \%$ vs. $36 \%, \mathrm{P}<0.0001)$. Another relevant finding in diabetics was the presence of a more extensive and severe CAD. In particular, diabetic patients with obstructive CAD had a ten times higher risk of mortality than non-diabetic patients (26).

In a nutshell, obstructive CAD resulted to be associated with a significantly increased rate of all-cause mortality and MACE. CONFIRM registry highlights that, in asymptomatic patients, CCT findings did not add any diagnostic benefit if added to a model consisting of both CCS and conventional risk factors. In symptomatic patients, instead, CCS didn't add incremental prognostic information to CCT and the survival probability worsens with the number of coronary arteries involved by obstructive CAD. Importantly, patients with normal coronary arteries at CCT have no MACE occurrence and present an excellent prognosis. Moreover, the CONFIRM registry points up the clinical relevance of statin assumption for the reduction of all-cause mortality.

Furthermore, the CONFIRM score is a tool of clinical utility deriving from the CONFIRM study.

Novel prognostic endpoints with longer follow-up are then expected by the estimated completion date of the study in January 2026.

\section{Associated features with acute coronary syndrome: the ICONIC study}

The ICONIC (Incident COroNary Syndromes Identified by Computed Tomography) study is a nested case control study in patients without known CAD and already enrolled in the CONFIRM registry.

The aim of the study was to identify coronary plaque features associated with precursors of acute coronary 
syndrome (ACS). Authors included 25,251 patients with no history of CAD (i.e., no revascularization or myocardial infarction) undergoing CCT with a mean follow-up of $3.4 \pm 2.1$ years. Patients with ACS were matched 1:1 to controls with no ACS. Patients with ACS didn't show significant differences from controls for total, calcified or fibrous plaque volumes, however they showed more fibro-fatty and necrotic core volumes. The maximal crosssectional plaque burden was also significantly higher in cases than in the controls $(66.1 \% \pm 25.8 \%$ vs. $56.5 \% \pm 28.7 \%$, $\mathrm{P}<0.001$ ), with no significant differences in the mean plaque burden. Per-lesion results showed the role of plaque burden together with some plaque features. The precursors of the culprit lesions showed greater plaque volume and length, as well as greater diameter stenosis \%, cross-sectional plaque burden, composition-specific plaque volumes, and prevalence of high-risk plaques (positive remodelling, low attenuation plaque, spotty calcification) (Figure 1). Only a minority of culprit lesions determined significant narrowing of coronary lumen. Patients who experienced an ACS showed more prominent atherosclerotic plaque softness; however, patients with ACS did not present differences from controls for atherosclerotic plaques at sites of bifurcation or tortuosity (27). Concerning gender differences, the ICONIC study didn't show any significant differences in culprit lesion precursors detected by CCT (28).

In conclusion, the ICONIC study focuses on the characteristics of coronary plaque studied with CCT beyond the degree of stenosis, underlying the clinical relevance of coronary plaques features. The ICONIC study demonstrates the enormous advantage of CCT in identifying risk features of coronary plaques in addition to the degree of luminal narrowing.

\section{The role of anatomic testing: PROMISE study and SCOT- HEART trial}

PROMISE (Prospective Multicenter Imaging Study for Evaluation of Chest Pain) is the first study designed to investigate the relevance at an entry level of non-invasive anatomical or functional tests in patients with suspected CAD. PROMISE study finds out if a test may also influence patient's final outcome. Patients with chest pain at lowto intermediate-risk were included and randomized to evaluation with an anatomical versus a functional strategy. The anatomical test chosen was the CCT, while the functional tests were different, with a clear prevalence of myocardial perfusion imaging (67\%), followed by stress echocardiography (22\%) and finally by exercise ECG stress test $(10 \%)$. Physical exercise was the type of stressor prevalent with respect to the pharmacological one. The primary hypothesis of the study was that cardiac events (a combination of death from any cause, myocardial infarction, hospitalization for unstable angina and major periprocedural complications) at 2 years of median follow-up would have been significantly lower in the CCT group compared to patients assigned to conventional functional strategy. However, the study didn't show significant difference for the predetermined outcomes, fully acknowledging the functional tests in the initial work-up of symptomatic patients for suspected CAD (29). The economic costs of CCT were associated with a small, but non-significant increase with respect to functional testing (30).

Secondary end points included a combination of the primary end point or invasive catheterization with no obstructive $\mathrm{CAD}$, and radiation exposure; exposure to ionizing radiation was considered in the 90 days after randomization including the exposure due to all procedures with ionizing radiation.

The functional strategy compared to the anatomical one was associated with a lower incidence of invasive coronary angiograms (ICA), even if the functional testing group underwent more ICA with no obstructive CAD. More patients of the CCT group underwent revascularization compared to the other group.

Furthermore, the mean and the overall exposure were higher in the CCT group than in the functional-testing one, although the median exposure resulted higher in the functional testing group (31).

In the same trial authors concluded to support the prognostic value of CAD-RADS (Coronary Artery Disease Reporting and Data System) as a standard reporting system for CCT (32). The role of CCT was not particularly emphasized in the PROMISE study; the results are somewhat in contrast to other large trials.

PROMISE demonstrates that the non-invasive strategy determines a reduction of invasive coronary angiography together with a lower overall dose.

The biological costs associated with invasive procedures, such as coronary angiography, together with the overall dose are important factors to be considered in choosing the diagnostic and therapeutic work-up.

The SCOT-HEART (Scottish COmputed Tomography of the HEART) trial is a multi-centre randomized 
controlled trial on the use of CCT in patients with chest pain and suspected CAD (33).

In this study 4,146 patients with suspected angina pectoris were randomized to standard of care alone or standard of care plus CCT; patients were followed-up for symptoms, management, and outcomes $(33,34)$. 1,778 subjects underwent CCT (34). The first outcome of the study was the number of patients with a diagnosis of angina caused by CAD at 6 weeks. Long-term outcomes included death, myocardial infarction, revascularizations, and hospitalization for chest pain, cerebrovascular and peripheral vascular diseases. Results at 6 weeks reported that CCT improved the certainty (RR 2.56, 95\% CI: $2.33-$ $2.79 ; \mathrm{P}<0.0001)$ and frequency $(1.09 ; 1.02-1.17 ; \mathrm{P}=0.0172)$ of the diagnosis of CAD in the CCT group, if compared to the group of standard of care alone; furthermore, an increase of certainty $(1.79 ; 1.62-1.96 ; \mathrm{P}<0.0001)$, in absence of effects on the frequency $(0.93 ; 0.85-1.02 ; \mathrm{P}=0.1289)$, of the diagnosis of angina due to CAD was also described. The results translated into a variation in planning of investigations and treatments. In particular, at 6 weeks the diagnosis of CAD had a change in $27 \%$ of patients in the CCT group (vs. $1 \%$ of patients assigned to standard of care alone). CCT determined the withdrawal of 121 functional stress tests and 29 invasive coronary angiograms (ICA). However, CCT determined 94 further ICA. Indeed, CCT was not associated with an increase of the proportion of coronary revascularizations (34). Moreover, the results of SCOT-HEART trial at 5 years were of greater clinical relevance than those shown at 6 months. At 5 years' followup the authors analysed deaths from CAD and the incidence of non-fatal myocardial infarctions in 20,254 patients. The rate of ICA became similar at 5 years' follow-up in the two groups. Surprisingly, the use of CCT in addition to the standard of care in patients with stable chest pain resulted in a significant reduction in CAD mortality and number of non-fatal myocardial infarctions at 5 years when compared to the standard of care alone (35).

Moreover, in considering these data, it must be highlighted that CCT group patients received more preventive therapies than the other group (35).

Another important finding is that only the $25 \%$ of patients who underwent CCT showed obstructive CAD with the $37 \%$ of patients showing normal coronary arteries (34); the low number of patients with obstructive coronary disease has to be taken into account in considering the number of cardiovascular events (35).
The SCOT-HEART Study also addressed the issue of non-occlusive atherosclerotic plaque or potentially unstable one. Many clinical papers have been published in the last decade on the description of the pathological characteristics of unstable plaques, but CCT is the only non-invasive tool able to display plaque features of coronary arteries. One of the main strengths of CCT is its capacity to identify atherosclerotic plaque characteristics, beyond the ability to identify indirect signs of ischemia. Some plaque characteristics have been identified as markers of vulnerability: positive remodelling, a large necrotic core, spotty calcifications, and a thin fibrous cap have been associated with plaque rupture $(36,37)$. Authors of the SCOT-HEART demonstrated that the abovementioned plaque characteristics were associated with a tripled risk of coronary heart death or nonfatal myocardial infarction. CCT is able to identify the positive remodelling of the coronary arteries, low attenuation plaques, spotty calcifications, and the so called "napkin ring" sign (38).

The "napkin ring" sign is a ring finger pattern of attenuation in coronary plaques associated with high-risk plaque (39-45). Furthermore, adverse plaque characteristics were associated with a higher cardiovascular risk score and higher CCS. Patients with a CCS $\geq 1,000$ Agatston Units showed an increase in coronary events, compared to patients without coronary artery calcifications. SCOT-HEART trial has proven that deaths due to CAD and nonfatal myocardial infarction were tripled in patients with adverse plaque features compared to patients without. Concerning coronary artery stenosis, patients with obstructive CAD had a doubled expectation to suffer from coronary death or nonfatal myocardial infarction. Obstructive CAD, together with adverse plaques CT features, is responsible of the highest event probability of cardiac events (38). ICA has the advantage of being an interventional technique, but it is unable to visualize plaque features (i.e., unstable plaque features of not-occlusive CAD).

These data are linked to the fact that myocardial infarction is a complex and multifactorial disease, where vessel stenosis together with plaque features are to be considered.

SCOT-HEART trial points up the unique role of CCT in the prediction of cardiovascular events with plaque imaging beyond coronary artery stenosis analysis. It also demonstrated that the use of CCT in addition to the standard of care, in patients with stable chest pain, provided a significant reduction in mortality and in the number of non-fatal myocardial infarctions at 5 years. 


\section{Effects of statins on plaques: the PARADIGM registry}

The Paradigm registry (Progression of AtheRosclerotic PlAque DetermIned by Computed TomoGraphic Angiography Imaging) is a prospective and multinational study. The authors investigated the impact of statins on coronary atherosclerotic plaques detected at CCT. Pleiotropic effects of statins are well known; they include action on endothelial dysfunction, antioxidant and antiinflammatory properties, and stabilization of atherosclerotic plaques (46). This was a registry of patients who underwent serial CCT without history of CAD, with an interscan interval of $3.8 \pm 1.6$ years. Compared to controls, patients in therapy with statin showed a lower rate of advancement of the atheroma volume, but a more rapid progression of calcified volume. Furthermore, patients under statins showed a lower rate of progression of non-calcified plaque volume and a lower incidence of high-risk plaques. Statin treatment doesn't affect stenosis percentage, but causes plaque changes. In particular, statins may cause plaque stabilization with calcifications onset and a reduction of instability findings (47).

\section{Impact of fractional flow reserve by CCT: the PLATFORM study}

The PLATFORM (Prospective Longitudinal Trial of FFR: Outcome and Resource Impacts) is a prospective cohort study that evaluated the impact of fractional flow reserve by CCT (FFRCT) in a population of 584 patients with new onset chest pain who underwent usual care testing (287 patients) or FFRCT (297 patients).

Optimal medical therapy (OMT) was encouraged in all subjects.

The primary endpoint was the rate of ICA within 90 days showing non-obstructive $\mathrm{CAD}$ in patients with already planned invasive testing in both groups.

Secondary endpoints included MACE at 90 days and unplanned hospitalization for chest pain followed by urgent revascularization.

One of the main results of the PLATFORM trial was that, following FFRCT results, ICA was annulled in $61 \%$.

ICA resulting in non-obstructive $\mathrm{CAD}$ was superior in usual care arm group compared to FFRCT one and no differences were found in the rate of revascularization in the two groups (48).

One-year outcome didn't show differences in term of clinical outcome in the two groups, even if costs and resource utilization were lower in the FFRCT group (49).

Therefore, FFRCT is still used in a few centres but its use could be justified by the reduction of costs and resources used.

\section{Breakthrough of CCT in the clinical scenario}

Ischemic heart disease is a complex process in which atherosclerosis is only one player of a complex disease in which ischemic process can take place even without vessel stenosis (50).

Starting from this assumption, the dualism between the ischemia detection by functional testing and the visualization of the coronary stenosis with anatomic CCT are subject of an interesting debate. In this context, the recent ISCHEMIA (International Study of Comparative Health Effectiveness With Medical and Invasive Approaches) trial provided further supportive evidence to the use of CCT. The ISCHEMIA is a multicenter and randomized controlled trial with 5,179 participants with moderate or severe ischemia detected on stress testing. Stress tests included myocardial perfusion imaging, echocardiography, exercise ECG test and cardiac magnetic resonance. Authors aimed to investigate what is the prognosis of coronary revascularization (through bypass surgery or percutaneous intervention) compared to OMT. A blinded CCT was performed in order to identify and exclude participants with significant unprotected left main disease $(\geq 50 \%$ stenosis) or those without obstructive CAD ( $<50 \%$ stenosis in all major coronary arteries). Patients with stable ischemic heart disease and moderate to severe ischemia were randomly assigned to routine invasive treatment or to optimal medical therapy, with invasive treatment only when OMT failed. The main goal of the study was to determine if an initial strategy with ICA and appropriate revascularization may reduce cardiac events compared to an initial strategy of OMT alone and catheterization only in patients with OMT failure (mean follow-up 3.3 years). Several endpoints were further included in the study such as to determine whether an initial invasive strategy can reduce cardiovascular events and symptoms, stroke, and all-cause mortality (15). The ISCHEMIA trial demonstrated that an initial invasive strategy did not reduce the risk of cardiovascular deaths (51). 318 events were registered in the ICA group $v s .352$ events in the OMT group. The event rates were $5.3 \%$ vs. $3.4 \%$ (ICA vs. OMT 
groups) at 6 months, and $16.4 \%$ vs. $18.2 \%$ at 5 years with no benefit in term of reduction of mortality or myocardial infarction in the ICA group $(52,53)$. However, the OMT group was not fully conservative because $23 \%$ of patients underwent ICA with revascularization. The invasive strategy led to a significant reduction in spontaneous myocardial infarction and to a better life quality. One of the main results that emerge from this study is that the functional testing was not always able to identify anatomically stenosis confidently. Despite the study was not mainly designed on CCT, the ISCHEMIA trial provides further evidences about the use of CCT as a first-line test for the assessment of CAD (54). The revascularization strategy must be carefully considered also with reference to the medical therapy and overall patient's health status $(55,56)$.

The release of the updated National Institute for Health and Care Excellence (NICE) guidelines in 2016 has revealed in advance this scenario of optimized cost-efficacy. The NICE guidelines for the first time recommended the use of CCT as the first-line investigation for suspected symptomatic CAD $(57,58)$. The high negative predictive value of CCT and its low invasiveness represented the greatest contributors in CCT expansion. In the past, ICA has been considered as the gold standard test to define CAD; nonetheless, its economic costs and procedural risks represented a brake on its take-off in the daily clinical practise, giving even more space to CCT. In the last decade, CCT has significantly improved its diagnostic accuracy through an enhanced spatial and temporal resolution, as well as a substantial reduction of radiation dose exposure. The NICE guidelines introduced the use of CCT as a firstline investigation in all patients with symptoms (atypical or typical angina) or with electrocardiographic anomalies suggestive of ischemia. The NICE analysed the costeffectiveness of different diagnostic tests of CAD (including cardiac magnetic resonance, ICA, single-photon emission computed tomography, CCT, echocardiography) and demonstrated that a first-line testing strategy using CCT has the lowest economic cost. Beyond economic issues, the ideal diagnostic test should be able to reduce MACE, stratifying the risk of patients into different strategies of treatment (58). NICE guidelines have several practical consequences: first, the need to deliver the required number of CCT examinations and therefore the need for adequate investments in this field; second, the need to train cardiac radiologists in reporting CCT; third, the increase of research investments to further reduce the dose of ionizing radiations (58).

Another fundamental step forward in the construction of the diagnostic pyramid of stable CAD has been achieved with the novel 2019 European Society of Cardiology (ESC) guidelines (59).

Non-invasive functional imaging for myocardial ischaemia or CCT is recommended as the initial test in symptomatic patients in whom obstructive CAD cannot be excluded from the clinical evaluation alone (Class Ib). CCT is preferred in patients with a lower probability of $\mathrm{CAD}$, in absence of previous diagnosis in which there is a high probability of obtaining diagnostic images. Functional testing for the identification of myocardial ischemia is recommended if the CCT has shown results of uncertain functional significance or if the examination has not been diagnostic (Class $\mathrm{Ib})$. On the other hand, ICA is recommended as an alternative test in patients with high clinical suspicion, severe symptomatology not responsive to medical therapy, or with typical angina triggered by a low level of exercise together with a clinical examination indicating a high risk of events (59).

Large clinical trials over CCT provided novel understandings and insights (Table 3), which are fundamental for a breakthrough in the work-up of stable CAD (Figure 2).

The direction in which we are going to is that of targeted therapy, including pharmacological one, based on the type of atherosclerotic disease and patients' clinical conditions.

The CCT, with its ability to characterize the plaque, is able to guide revascularization but also to provide indications for the choice of "tailored" pharmacological therapy.

The use of the FFRCT, although it requires further scientific confirmation, could play an important role in this regard, together with technological advances; in this context new large trials are required.

\section{Conclusions}

The role of CCT has shifted from a technique capable of detecting coronary artery stenosis such as ICA to a technique capable of plaque characterization. It has been demonstrated that the coronary risk is not only linked to the percentage of stenosis but also to certain vulnerability parameters of plaques. In the last decade, the large trials redefined the role of CCT and functional testing.

Further updated documents and guidelines are expected over CCT. 
Table 3 Summary of the results of clinical trials over CCT

\begin{tabular}{|c|c|c|}
\hline Trial & Target & Main results \\
\hline PROMISE & $\begin{array}{l}\text { Impact of CCT on current } \\
\text { standards of care }\end{array}$ & $\begin{array}{l}\text { - Diagnostic and prognostic equivalence of anatomical strategy with CCT versus the } \\
\text { standard of care with functional testing } \\
\text { - Increase of cardiac catheterizations in the CCT group, despite the decrease of } \\
\text { catheterizations showing not obstructive CAD }\end{array}$ \\
\hline CONFIRM & $\begin{array}{l}\text { Prognostic value of CCT in } \\
\text { several patients group }\end{array}$ & $\begin{array}{l}\text { - No MACE in patients with normal coronary arteries at CCT } \\
\text { - Increase of MACE with the severity of CAD (i.e., nonobstructive and obstructive) } \\
\text { detected at CCT }\end{array}$ \\
\hline PARADIGM & $\begin{array}{l}\text { Progression of CAD at CCT and } \\
\text { impact of treatment with statins } \\
\text { on plaques }\end{array}$ & $\begin{array}{l}\text { - Ability of CCT to depict plaque features of instability } \\
\text { - Coronary plaque stabilization detected at CCT in patients treated with statins }\end{array}$ \\
\hline PLATFORM & $\begin{array}{l}\text { Impact of fractional flow reserve } \\
\text { by CCT (FFRCT) in patients with } \\
\text { new onset chest pain }\end{array}$ & $\begin{array}{l}\text { - Reduction of invasive coronary angiography following FFRCT } \\
\text { - Reduction of costs and resource utilization after FFRCT }\end{array}$ \\
\hline ISCHEMIA & $\begin{array}{l}\text { Outcome of invasive strategy in } \\
\text { stable patients with ischemia on } \\
\text { stress testing }\end{array}$ & $\begin{array}{l}\text { - Similar outcomes of invasive and conservative approaches in stable patients } \\
\text { - Reliability of anatomic testing with CCT for the evaluation of symptomatic patients } \\
\text { suspected of having CAD }\end{array}$ \\
\hline
\end{tabular}

CCT, cardiac computed tomography; CAD, coronary artery disease; MACE, major adverse cardiovascular events; FFRCT, fractional flow reserve derived from $\mathrm{CT}$.

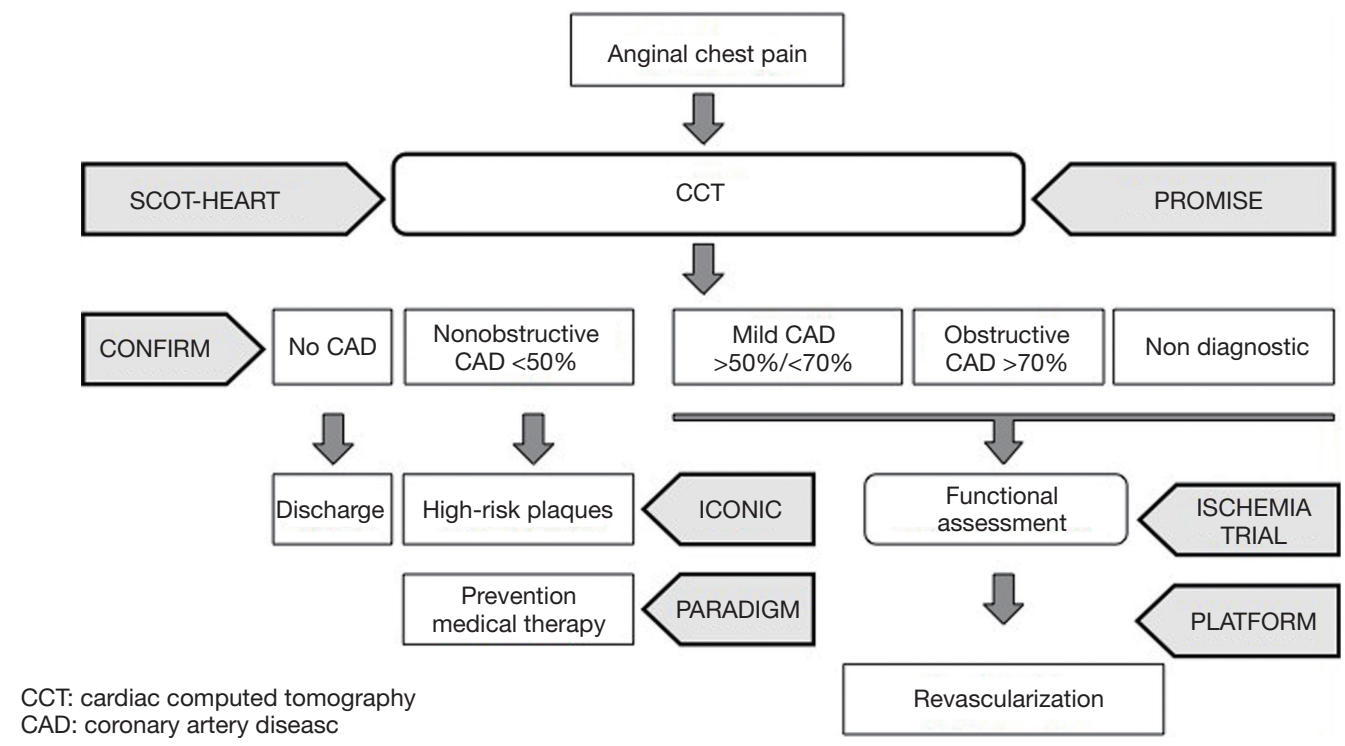

Figure 2 Breakthrough in the work-up of stable CAD with reference to large clinical trials. 


\section{Acknowledgments}

Funding: None.

\section{Footnote}

Provenance and Peer Review: This article was commissioned by the editorial office, Cardiovascular Diagnosis and Therapy for the series "Impact of Cardiac CT in Clinical Practice". The article has undergone external peer review.

Reporting Checklist: The authors have completed the Narrative Review reporting checklist. Available at http:// dx.doi.org/10.21037/cdt-20-526

Conflicts of Interest: All authors have completed the ICMJE uniform disclosure form (available at http://dx.doi. org/10.21037/cdt-20-526). The series "Impact of Cardiac CT in Clinical Practice" was commissioned by the editorial office without any funding or sponsorship. FC served as the unpaid Guest Editor of the series and serves as an unpaid editorial board member of Cardiovascular Diagnosis and Therapy from Jul 2019 to Jun 2021. The authors have no other conflicts of interest to declare.

Ethical Statement: The authors are accountable for all aspects of the work in ensuring that questions related to the accuracy or integrity of any part of the work are appropriately investigated and resolved.

Open Access Statement: This is an Open Access article distributed in accordance with the Creative Commons Attribution-NonCommercial-NoDerivs 4.0 International License (CC BY-NC-ND 4.0), which permits the noncommercial replication and distribution of the article with the strict proviso that no changes or edits are made and the original work is properly cited (including links to both the formal publication through the relevant DOI and the license). See: https://creativecommons.org/licenses/by-nc-nd/4.0/.

\section{References}

1. Available online: https://www.who.int/health-topics/ cardiovascular-diseases/\#tab=tab_1

2. Nikolaou K, Knez A, Rist C, et al. Accuracy of 64-MDCT in the diagnosis of ischemic heart disease, AJR Am J Roentgenol 2006;187:111-7.

3. Ehara M, Surmely JF, Kawai M, et al. Diagnostic accuracy of 64-slice computed tomography for detecting angiographically significant coronary artery stenosis in an unselected consecutive patient population: comparison with conventional invasive angiography, Circ J 2006;70:564-71.

4. Weustink AC, Meijboom WB, Mollet NR, et al.

Reliable high-speed coronary computed tomography in symptomatic patients. J Am Coll Cardiol 2007;50:786-94.

5. Leber AW, Johnson T, Becker A, et al. Diagnostic accuracy of dual-source multi-slice CT-coronary angiography in patients with an intermediate pretest likelihood for coronary artery disease. Eur Heart J 2007;28:2354-60.

6. Meijboom WB, Meijs MF, Schuijf JD, et al. Diagnostic accuracy of 64-slice computed tomography coronary angiography: a prospective, multicenter, multivendor study. J Am Coll Cardiol 2008;52:2135-44.

7. Cademartiri F, Maffei E, Palumbo A, et al. Diagnostic accuracy of computed tomography coronary angiography in patients with a zero calcium score. Eur Radiol 2010;20:81-7.

8. Opolski MP, Kim WK, Liebetrau C, et al. Diagnostic accuracy of computed tomography angiography for the detection of coronary artery disease in patients referred for transcatheter aortic valve implantation. Clin Res Cardiol 2015;104:471-80.

9. Lee j, Kim TH, Lee BK, et al. Diagnostic accuracy of lowradiation coronary computed tomography angiography with low tube voltage and knowledge-based model reconstruction. Sci Rep 2019;9:1308.

10. Available online: https://clinicaltrials.gov/ct2/show/study/ NCT01149590

11. Available online: https://clinicaltrials.gov/ct2/show/study/ NCT01174550

12. Available online: https://clinicaltrials.gov/ct2/show/study/ NCT01443637

13. Available online: https://clinicaltrials.gov/ct2/show/ NCT02959099

14. Available online: https://clinicaltrials.gov/ct2/show/ NCT02803411

15. Available online: https://clinicaltrials.gov/ct2/show/ NCT01943903

16. Available online: https://clinicaltrials.gov/ct2/show/study/ NCT01471522

17. Otaki Y, Berman DS, Min JK. Prognostic utility of coronary computed tomographic angiography. Indian Heart J 2013;65:300-10.

18. Min JK, Dunning A, Lin FY, et al. Age- and Sex-Related Differences in All-Cause Mortality Risk Based on Coronary Computed Tomography Angiography Findings 
Results From the International Multicenter CONFIRM

(Coronary CT Angiography Evaluation for Clinical

Outcomes: An International Multicenter Registry) of 23,854 Patients Without Known Coronary Artery Disease. J Am Coll Cardiol 2011;58:849-60.

19. Villines TC, Hulten EA, Shaw LJ, et al. Prevalence and severity of coronary artery disease and adverse events among symptomatic patients with coronary artery calcification scores of zero undergoing coronary computed tomography angiography: results from the CONFIRM (Coronary CT Angiography Evaluation for Clinical Outcomes: An International Multicenter) registry; J Am Coll Cardiol 2011;58:2533-40.

20. Cho I, Al'Aref SJ, Berger A, et al. Prognostic value of coronary computed tomographic angiography findings in asymptomatic individuals: a 6-year follow-up from the prospective multicentre international CONFIRM study. Eur Heart J 2018;39:934-41.

21. Gnanenthiran SR, Naoum C, Leipsic JA. Long-term prognostic utility of computed tomography coronary angiography in older populations. Eur Heart J Cardiovasc Imaging 2019;20:1279-86.

22. Opolski MP, Gransar H, Lu Y, et al. Prognostic value of chronic total occlusions detected on coronary computed tomographic angiography. Heart 2019;105:196-203.

23. Cho YK, Nam CW, Koo BK, et al. Usefulness of baseline statin therapy in non- obstructive coronary artery disease by coronary computed tomographic angiography: From the CONFIRM (COronary CT Angiography EvaluatioN For Clinical Outcomes: An InteRnationalMulticenter) study. PLoS One 2018;13:e0207194.

24. Hadamitzky M, Achenbach S, Al-Mallah M, et al. Optimized prognostic score for coronary computed tomographic angiography: results from the CONFIRM registry (COronary CT Angiography EvaluatioN For Clinical Outcomes: An InteRnational Multicenter Registry). J Am Coll Cardiol 2013;62:468-76.

25. Deseive S, Shaw LJ, Min JK, et al. Improved 5-year prediction of all-cause mortality by coronary CT angiography applying the CONFIRM score. Eur Heart J Cardiovasc Imaging 2017;18:286-93.

26. Rana JS, Dunning A, Achenbach S, et al. Differences in prevalence, extent, severity, and prognosis of coronary artery disease among patients with and without diabetes undergoing coronary computed tomography angiography: results from 10,110 individuals from the CONFIRM (COronary CT Angiography EvaluatioN For Clinical Outcomes): an InteRnational Multicenter Registry.
Diabetes Care 2012;35:1787-94.

27. Chang HJ, Lin FY, Lee SE, et al. Coronary Atherosclerotic Precursors of Acute Coronary Syndromes. J Am Coll Cardiol 2018;71:2511-22.

28. Dwivedi A, Shaw L, Lin F, et al. Association of sex with atherosclerotic plaque characteristics in precursors of culprit lesions: the iconic study. J Am Coll Cardiol 2018;71:A1640.

29. Gaibazzi N, Cademartiri F, Maffei E. PROCESSO AI GRANDI TRIAL: Lo studio PROMISE. Cardiol 2015;16:462-8.

30. Douglas PS, Hoffmann U, Lee KL, et al. PROspective Multicenter Imaging Study for Evaluation of chest pain: Rationale and design of the PROMISE trial. Am Heart J 2014;167:796-803.e1.

31. Douglas PS, Hoffmann U, Patel MR, et al. Outcomes of Anatomical versus Functional Testing for Coronary Artery Disease. N Engl J Med 2015;372:1291-300.

32. Bittner DO, Mayrhofer T, Budoff M, et al. Prognostic Value of Coronary CTA in Stable Chest Pain: CADRADS, CAC, and Cardiovascular Events in PROMISE. JACC Cardiovasc Imaging 2020;13:1534-45.

33. Newby DE, Williams MC, Flapan AD, et al. Role of multidetector computed tomography in the diagnosis and management of patients attending the rapid access chest pain clinic, The Scottish computed tomography of the heart (SCOT- HEART) trial: study protocol for randomized controlled trial. Trials 2012;13:184.

34. SCOT-HEART investigators. CT coronary angiography in patients with suspected angina due to coronary heart disease (SCOT-HEART): an open-label, parallel-group, multicentre trial. Lancet 2015;385:2383-91.

35. SCOT-HEART Investigators, Newby DE, Adamson PD, et al. Coronary CT Angiography and 5-Year Risk of Myocardial infarction. N Engl J Med 2018;379:924-33.

36. Cademartiri F, La Grutta L, Palumbo A, et al. Imaging techniques for the vulnerable coronary plaque. Radiol Med 2007;112:637-59.

37. Motoyama S, Kondo T, Sarai M, et al. Multislice computed tomographic characteristics of coronary lesions in acute coronary syndromes. J Am Coll Cardiol 2007;50:319-26.

38. Williams MC, Moss AJ, Dweck M, et al. Coronary Artery Plaque Characteristics Associated With Adverse Outcomes in the SCOT-HEART Study. J Am Coll Cardiol 2019;73:291-301.

39. Maurovich-Horvat P, Schlett CL, Alkadhi H, et al. The Napkin-Ring Sign Indicates Advanced Atherosclerotic Lesions in Coronary CT Angiography. JACC Cardiovasc 
Imaging 2012;5:1243-52.

40. Kashiwagi M, Tanaka A, Kitabata H, et al. Feasibility of noninvasive assessment of thin-cap fibroatheroma by multidetector computed tomography. JACC Cardiovasc Imaging 2009;2:1412-9.

41. Nakazawa G, Tanabe K, Onuma Y, et al. Efficacy of culprit plaque assessment by 64-slice multidetector computed tomography to predict transient no-reflow phenomenon during percutaneous coronary intervention. Am Heart J 2008;155:1150-7.

42. Tanaka A, Shimada K, Yoshida K, et al. Non-invasive assessment of plaque rupture by 64-slice multidetector computed tomography- comparison with intravascular ultrasound. Circ J 2008;72:1276-81.

43. Maurovich-Horvat P, Hoffmann U, Vorpahl M, et al. The napkin-ring sign: CT signature of high-risk coronary plaques? JACC Cardiovasc Imaging 2010;3:440-4.

44. Donnelly P, Maurovich-Horvat P, Vorpahl M, et al. Multimodality imaging atlas of coronary atherosclerosis. JACC Cardiovasc Imaging 2010;3:876-80.

45. Pflederer T, Marwan M, Schepis T, et al. Characterization of culprit lesions in acute coronary syndromes using coronary dual-source CT angiography. Atherosclerosis 2010;211:437-44.

46. Davignon J. Beneficial Cardiovascular Pleiotropic Effects of Statins. Circulation 2004;109:III39-43.

47. Lee SE, Chang HJ, Sung J, et al. Effects of Statins on Coronary Atherosclerotic Plaques: The PARADIGM Study. JACC Cardiovasc Imaging 2018;11:1475-84.

48. Douglas PS, Pontone G, Hlatky MA, et al. Clinical outcomes of fractional flow reserve by computed tomographic angiography-guided diagnostic strategies vs. usual care in patients with suspected coronary artery disease: the prospective longitudinal trial of $\mathrm{FFR}(\mathrm{CT})$ : outcome and resource impacts study. Eur Heart J 2015;36:3359-67.

49. Douglas PS, De Bruyne B, Pontone G, et al. 1-Year Outcomes of FFRCT-Guided Care in Patients With Suspected Coronary Disease: The PLATFORM Study. J Am Coll Cardiol 2016;68:435-45.

50. Marzilli M, Merz CN, Boden WE, et al. Obstructive

Cite this article as: Toia P, La Grutta L, Smeraldi T, Agnello F, Grassedonio E, Maffei E, Midiri M, Cademartiri F. Updated diagnostic \& prognostic paradigm for CAD: a narrative review. Cardiovasc Diagn Ther 2020;10(6):1979-1991. doi: 10.21037/cdt20-526 coronary atherosclerosis and ischemic heart disease: an elusive link!. J Am Coll Cardiol 2012;60:951-6.

51. Vorkas PA, Isaac G, Holmgren A, et al. Perturbations in fatty acid metabolism and apoptosis are manifested in calcific coronary artery disease: An exploratory lipidomic study. Int J Cardiol 2015;197:192-9.

52. Maron DJ, Hochman JS, Reynolds HR, et al. Initial Invasive or Conservative Strategy for Stable Coronary Disease. N Engl J Med 2020;382:1395-407.

53. Gawor M, Nagel E. Perfusion cardiovascular magnetic resonance as the first-line technique in patients with stable chest pain. Kardiol Pol 2020;78:98-104.

54. Leipsic A, Achenbach S. The ISCHEMIA Trial: Implication for Cardiac Imaging in 2020 and Beyond. Cardiothorac Imaging 2020;2:e200021.

55. Reynolds HR, Hochman JS. International Study of Comparative Health Effectiveness With Medical and Invasive Approaches - ISCHEMIA. Cardiothorac Imaging 2020.

56. Camici PG, Merz NB, Beltrame J, et al. Commentary The ISCHEMIA trial. Int J Cardiol 2020;304:1-4.

57. National Institute for Health and Clinical Excellence. Chest pain of recent onset: assessment and diagnosis of recent onset chest pain or discomfort of suspected cardiac origin (update). CG95. London: National Institute for Health and Clinical Excellence; 2016. The updated UK guideline that uses cost-utility analysis to recommend CTCA as the first-line investigation for suspected symptomatic coronary artery disease.

58. Moss AJ, Williams MC, Newby DE, et al. The Updated NICE Guidelines: Cardiac CT as the First-Line Test for Coronary Artery Disease. Curr Cardiovasc Imaging Rep 2017;10:15.

59. Knuuti J, Wijns W, Saraste A, et al. 2019 ESC Guidelines for the diagnosis and management of chronic coronary syndromes The Task Force for the diagnosis and management of chronic coronary syndromes of the European Society of Cardiology (ESC). Eur Heart J 2020;41:407-77. 